\title{
Four decades of research on alexithymia: moving toward clinical applications
}

\author{
Dalya Samur ${ }^{1}{ }^{*}$, Mattie Tops $^{1}$, Caroline Schlinkert ${ }^{1}$, Markus Quirin ${ }^{2}$, Pim Cuijpers ${ }^{1}$ and \\ Sander L. Koole ${ }^{1}$
}

${ }^{1}$ Department of Clinical Psychology, VU University Amsterdam, Amsterdam, Netherlands

2 Institute of Psychology, University of Osnabrück, Osnabrück, Germany

${ }^{*}$ Correspondence: dalyasamur@gmail.com

Edited by:

Lorenza S. Colzato, Leiden University, Netherlands

Reviewed by:

Roberta Sellaro, University of Leiden, Netherlands

Keywords: alexithymia, treatment, implications, oxytocin, neurofeedback, emotion processing

Virtually everyone has experienced from time to time how hard it can be to put one's feelings into words. Yet, for some individuals, this task is especially daunting. Such individuals are characterized by high levels of alexithymia ("no words for feelings"). Alexithymia is a personality dimension that involves both cognitive deficits, including difficulties in recognizing, describing, and distinguishing feelings from bodily sensations of emotional arousal, and affective deficits, including difficulties in emotionalizing and fantasizing (Bermond et al., 2007). Alexithymia is implicated in a wide variety of psychological problems, such as depression (Honkalampi et al., 2000) and schizophrenia (Rotenberg, 1994). Moreover, emotional deficits in autism spectrum disorder may be largely driven by alexithymia (Bird and Cook, 2013). Finally, alexithymia is associated with suicidality (Hintikka et al., 2004), increased psychosomatic complaints (Lane, 2008) and elevated mortality rates (Tolmunen et al., 2010).

Since the term "alexithymia" was introduced some four decades ago by Sifneos (1973), individual differences in alexithymia have been the focus of considerable research efforts. Indeed, at the time of writing this article (October 14, 2013), we counted more than 1400 articles in the PsychInfo database with "alexithymia" in the title or abstract. This research has analyzed many different facets of alexithymia, including its behavioral, linguistic, physiological, and neurological correlates (for recent reviews, see Taylor and Bagby, 2004; Kano and Fukudo, 2013; Nowakowski et al., 2013; van der Velde et al., 2013) as well as its assessment techniques (for a review, see Lumley et al., 2007). The accumulated knowledge based on the formation and assessment provides valuable insights into alexithymia. Nevertheless, researchers have so far taken few steps to translate these insights into treatments and interventions.

The current lack of translational work in alexithymia research seems highly unfortunate, considering that epidemiological studies indicate that as many as $10 \%$ of the general population may be characterized by levels of alexithymia that are sufficiently high to qualify as pathological (Salminen et al., 1999). Basic research remains necessary to answer unresolved questions about alexithymia. Nevertheless, a number of empirical findings on alexithymia now seem sufficiently well-established to consider their clinical application. Ogrodniczuk et al. (2011) found that high-alexithymic individuals seeking a treatment are as open as low-alexithymic individuals to receiving psychotherapy. Moreover, several studies have shown that alexithymia scores may decline during psychotherapy and such changes are correlated with improvement in therapy. For instance, high-alexithymic individuals may benefit from cognitive behavioral therapy (Spek et al., 2008) and also seem responsive to group therapy (e.g., Beresnevaite, 2000; Ogrodniczuk et al., 2011). As Ogrodniczuk et al., concluded, "This implies that alexithymic patients can at least partly develop some capacity to recognize their feelings and to communicate them to other people, thus enhancing their ability to use emotional information to guide adaptive behavior."
Nevertheless, to the best of our knowledge, there exists no treatment specifically designed to overcome the problems associated with alexithymia. Furthermore, many existing forms of psychotherapy may be less than optimal for helping highalexithymic individuals, given that they typically achieve poorer outcomes in psychotherapy than low-alexithymic individuals (Bach and Bach, 1995; McCallum et al., 2003; Ogrodniczuk et al., 2011). It therefore seems prudent to develop treatments that are specifically designed to overcome the problems associated with alexithymia. Offering such treatments to high-alexithymic individuals may significantly boost the effectiveness of psychotherapy within this group.

We therefore call upon researchers to consider more systematically how basic research findings may be translated into tools for improving the fate of alexithymic individuals. To facilitate the translation process, we briefly describe some promising ways in which alexithymia research may be converted into clinical interventions. Notably, our discussion is selective rather than exhaustive. We aim to identify the "low hanging fruit" that can be profitably explored by researchers who are interested in developing more effective evidence-based treatments for alexithymia.

\section{ALEXITHYMIA AND EMOTION PROCESSING}

Deficits in emotional processing are central to the notion of alexithymia. Indeed, behavioral experiments have shown that alexithymia is linked to poorer recognition of emotional expressions in faces 
(Grynberg et al., 2012; Cook et al., 2013) and lower recall for emotional material (Luminet et al., 2006). One straightforward clinical use of these tasks may lie in helping practitioners to refine their diagnosis of alexithymia. To this end, it will be important to develop standardized emotion processing tasks that have norm scores for appropriate populations.

Beyond diagnosis, however, an exciting possibility is that emotional processing tasks may be used to train emotional skills among alexithymic individuals. Here, an analogy may be drawn with research on attentional biases in individuals with anxiety disorders (see Mathews and MacLeod, 2002). Initial research showed that highanxious individuals display an attentional bias toward threatening stimuli. The same tasks that were used to demonstrate this attentional bias were subsequently modified by researchers to train high-anxious individuals to shift their attention away from threatening stimuli. In an analogous manner, experimental tasks that have so far been used to demonstrate deficient emotion processes among alexithymic individuals may be modified to overcome these deficiencies. For instance, alexithymic individuals may be trained to better recognize emotional expressions in faces (see Cook et al., 2013, for a relevant task) and to have better recollection of emotional memories (see Luminet et al., 2006). Examining whether such training tasks may benefit alexithymic individuals seems a worthy question for future research.

\section{ALEXITHYMIA AND LANGUAGE}

Among human beings, the ability to express emotions requires processing at the linguistic level. Thus, linguistic processing plays a key role in alexithymia. Indeed, alexithymic people display impaired processing of emotional language at multiple levels. At a basic perceptual level, alexithymic people display poorer sensitivity to the emotional meanings of language. For instance, relative to low-alexithymic individuals, high-alexithymic individuals showed less facilitation from priming emotional contexts on the processing of emotion words (Suslow and Junghanns, 2002). Alexithymic people are further impaired in the perception and processing of speech prosody, or melody of speech, with emotional content (Goerlich et al., 2013). One possible linguistic intervention might consist of training alexithymic individuals in affect labeling that is, in lexicalizing emotional aspects of emotional stimuli and events. Research among general populations (which did not assess alexithymia) indicates that affect labeling improves emotion regulation (Lieberman et al., 2011). Thus, affect labeling could be an effective antidote against alexithymia.

At a communicative level, alexithymic individuals further demonstrate problems in emotional language production and comprehension. In particular, alexithymic individuals display a limited ability to talk about interpersonal relationships (Meganck et al., 2009), describe others' emotional experiences (Bydlowski et al., 2005), and understand the emotions of others (Moriguchi et al., 2006; Swart et al., 2009). In personal narratives, alexithymic individuals tend to use vocabulary of limited complexity and their emotional discourse lacks any vivid descriptions (Meganck et al., 2009). Alexithymia is also linked to concretist thinking and avoidance of metaphors (Kreitler, 2002).

The impoverished linguistic style of alexithymic individuals may be enriched by training them to use metaphors (Kousta et al., 2011) and mental imagery (Holmes and Mathews, 2010). A recent series of innovative experiments by Kidd and Castano (2013) suggests that reading literary fiction (as opposed to non-literary texts) can improve people's ability to identify and understand other's subjective states. These are among the primary social-cognitive abilities that are impaired among alexithymic individuals. As such, the intriguing possibility arises that alexithymic individuals may overcome some of their communicative difficulties by reading works of literary fiction, and perhaps also by receiving appropriate training in literary skills (e.g., poetry or creative writing).

\section{OXYTOCIN AND NEUROFEEDBACK}

Recent years have seen a rapid growth of physiological and neuroscientific studies of alexithymia. Even though research within these areas is relatively novel, some of this research shows some promising therapeutic potential.
The neuropeptide oxytocin has been found to alter the perceptual salience and/or processing of social cues and to increase socio-emotional communication and trust (Carter, 1998; Bartz et al., 2011). Although oxytocin is naturally produced by the body, it can also be externally administered by inhaling it through the nose. Administration studies indicate that oxytocin fosters social-cognitive processes that are impaired among alexithymic individuals. For instance, a recent study showed that intranasal oxytocin increases people's willingness to verbally share painful emotions (Lane et al., 2013). Importantly, oxytocin did not simply make people more talkative but instead specifically increased the willingness to share emotions. Preclinical and clinical studies have identified important links between oxytocin and a range of psychiatric disorders, and have now started to directly assess its therapeutic potential in treating socio-emotional functioning deficits (Matsuzaki et al., 2012; Macdonald and Feifel, 2013; Tops et al., 2013). Most relevant here, a recent study suggests that the social-cognitive benefits of oxytocin are particularly pronounced among individuals who score high (rather than low) on alexithymia (Luminet et al., 2011). Oxytocin may impact on central aspects of alexithymia such as the decreased recognition, expression, and consequently sharing of emotions. Although more research is clearly needed, these preliminary findings suggest that intranasal oxytocin might have therapeutic benefits, perhaps as an adjunct to therapy or training.

Neuroimaging research has further linked alexithymia to decreased neural activations to emotional stimuli [see van der Velde et al. (2013), for a metaanalysis]. Interventions might target these specific neural areas using specialized techniques. For instance, online transcranial magnetic stimulation can be used to activate brain areas that are involved in emotion as well as language [e.g., the inferior frontal gyrus (IFG); Hartwigsen et al., 2010; Hoekert et al., 2010]. Moreover, brain areas (e.g., the anterior insula) that have been implicated in empathy, emotion, interoceptive awareness, and alexithymia (e.g., Bird et al., 2010; Bernhardt et al., 2013) and areas involved in emotion and language (IFG; Rota et al., 2009) can 
be trained by neurofeedback using realtime functional magnetic resonance imaging (e.g., Caria et al., 2010). Alternatively, neurofeedback may be provided through low-cost technology such as near-infrared spectroscopy (Mihara et al., 2012), which can detect relevant functional activation in areas such as the IFG (Takei et al., 2013). Training of anterior insula activation also changes the appraisal of emotional stimuli (Caria et al., 2010) and in patients with schizophrenia it led to changes in the perception of emotions and modulations of the brain network connectivity (Ruiz et al., 2013). These findings open the door to further studies in alexithymia and psychiatric populations, and possible therapeutic applications.

\section{CONCLUSIONS AND OUTLOOK}

The pains of putting one's feelings into words are a universal human experience that lies at heart of the personality dimension of alexithymia. Over the last four decades, the alexithymia construct has inspired volumes of research. The resulting wealth of empirical findings has illuminated many aspects of alexithymia, but so far has not resulted in the development of new, evidence-based treatments for improving the life of alexithymic individuals. Nevertheless, as we have outlined in this article, behavioral, linguistic, and neuroscience research on alexithymia seem to have progressed to a point where they may be translated into effective treatments for alexithymic individuals. These treatments may be delivered in innovative formats, such as Internet-based programs. These programs might be especially appealing to alexithymic individuals, because online communication provides a way to keep interpersonal contact at a minimum, lowering the need for openly sharing one's emotions. Treatments for alexithymia may be offered to complement existing clinical treatments, to permit high alexithymic individuals to derive more benefits from psychotherapy.

With this outline, we hope to stimulate researchers to invest more in the development of evidence-based treatments for alexithymia, and to evaluate these treatments in terms of their effectiveness. The findings of evaluative research may in turn inform basic research, creating a dynamic dialogue between practitioners and basic researchers. After four decades of basic research on alexithymia, the time seems ripe to move toward clinical applications.

\section{ACKNOWLEDGMENTS}

This research was supported by a Veni grant of the Netherlands Organization for Scientific Research (NWO) (45107-013) awarded to Mattie Tops and a Consolidator Grant of the European Research Council (ERC-2011StG_20101124) awarded to Sander L. Koole.

\section{REFERENCES}

Bach, M., and Bach, D. (1995). Predictive value of alexithymia: a prospective study in somatizing patients. Psychother. Psychosom. 64, 43-48. doi: 10.1159/000288989

Bartz, J. A., Zaki, J., Bolger, N., and Ochsner, K. N. (2011). Social effects of oxytocin in humans: context and person matter. Trends. Cogn. Sci. 15, 301-309. doi: 10.1016/j.tics.2011.05.002

Beresnevaite, M. (2000). Exploring the benefits of group psychotherapy in reducing alexithymia in coronary heart disease patients: a preliminary study. Psychother. Psychosom. 69, 117-122. doi: 10.1159/000012378

Bermond, B., Clayton, K., Liberova, A., Luminet, O., Maruszewski, T., Ricci Bitti, P. E., et al. (2007). A cognitive and an affective dimension of alexithymia in six languages and seven populations. Cogn. Emot. 21, 1125-1136. doi: 10.1080/02699930601056989

Bernhardt, B. C., Valk, S. L., Silani, G., Bird, G., Frith, U., and Singer, T. (2013). Selective disruption of sociocognitive structural brain networks in autism and alexithymia. Cereb. Cortex. doi: 10.1093/cercor/bht182. [Epub ahead of print].

Bird, G., and Cook, R. (2013). Mixed emotions: the contribution of alexithymia to the emotional symptoms of autism. Transl. Psychiatry 3, e285. doi: $10.1038 /$ tp.2013.61

Bird, G., Silani, G., Brindley, R., White, S., Frith, U., and Singer, T. (2010). Empathic brain responses in insula are modulated by levels of alexithymia but not autism. Brain 133, 1515-1525. doi: 10.1093/brain/awq060

Bydlowski, S., Corcos, M., Jeammet, P., Paterniti, S., Berthoz, S., Laurier, C., et al. (2005). Emotionprocessing deficits in eating disorders. Int. J. Eat. Disord. 37, 321-329. doi: 10.1002/eat.20132

Caria, A., Sitaram, R., Veit, R., Begliomini, C., and Birbaumer, N. (2010). Volitional control of anterior insula activity modulates the response to aversive stimuli. A real-time functional magnetic resonance imaging study. Biol. Psychiatry 68, 425-432. doi: 10.1016/j.biopsych.2010. 04.020

Carter, C. S. (1998). Neuroendocrine perspectives on social attachment and love. Psychoneuroendocrinology 23, 779-818. doi: 10.1016/S0306-4530(98)00055-9

Cook, R., Brewer, R., Shah, P., and Bird, G. (2013). Alexithymia, not autism, predicts poor recogni- tion of emotional facial expressions. Psychol. sci. 24, 723-732. doi: 10.1177/0956797612463582

Goerlich, K. S., Witteman, J., Schiller, N. O., van Heuven, V. J., Aleman, A., and Martens, S. (2013). Blunted feelings: alexithymia is associated with a diminished neural response to speech prosody. Soc. Cogn. Affect. Neurosci. doi: 10.1093/scan/nst075. [Epub ahead of print].

Grynberg, D., Chang, B., Corneille, O., Maurage, P., Vermeulen, N., Berthoz, S., et al. (2012). Alexithymia and the processing of emotional facial expressions (EFEs): systematic review, unanswered questions and further perspectives. PLoS ONE 7:e42429. doi: 10.1371/journal.pone.0042429

Hartwigsen, G., Price, C. J., Baumgaertner, A., Geiss, G., Koehnke, M., Ulmer, S., et al. (2010). The right posterior inferior frontal gyrus contributes to phonological word decisions in the healthy brain: evidence from dual-site TMS. Neuropsychologia 48, 3155-3163. doi: 10.1016/j.neuropsychologia.2010.06.032

Hintikka, J., Honkalampi, K., Koivumaa-Honkanen, H., Antikainen, R., Tanskanen, A., Haatainen, K., et al. (2004). Alexithymia and suicidal ideation: a 12-month follow-up study in a general population. Compr. Psychiatry 45, 340-345. doi: 10.1016/j.comppsych.2004.06.008

Hoekert, M., Vingerhoets, G., and Aleman, A. (2010). Results of a pilot study on the involvement of bilateral inferior frontal gyri in emotional prosody perception: an rTMS study. BMC Neurosci. 11:93. doi: 10.1186/1471-2202-11-93

Holmes, E. A., and Mathews, A. (2010). Mental imagery in emotion and emotional disorders. Clin. Psychol. Rev. 30, 349-362. doi: 10.1016/j.cpr.2010.01.001

Honkalampi, K., Hintikka, J., Tanskanen, A., Lehtonen, J., and Viinamäki, H. (2000). Depression is strongly associated with alexithymia in the general population. J. Psychosom. Res. 48, 99-104. doi: 10.1016/S0022-3999(99)00083-5

Kano, M., and Fukudo, S. (2013). The alexithymic brain: the neural pathways linking alexithymia to physical disorders. Biopsychosoc. Med. 7:1. doi: 10.1186/1751-0759-7-1

Kidd, D. C., and Castano, E. (2013). Reading literary fiction improves theory of mind. Science 342, 377-380. doi: 10.1126/science.1239918

Kousta, S. T., Vigliocco, G., Vinson, D. P., Andrews, M., and Del Campo, E. (2011). The representation of abstract words: why emotion matters. J. Exp. Psychol. Gen. 140, 14. doi: 10.1037/a0021446

Kreitler, S. (2002). The psychosemantic approach to alexithymia. Pers. Individ. Diff. 33, 393-407. doi: 10.1016/S0191-8869(01)00163-5

Lane, A., Luminet, O., Rimé, B., Gross, J. J., de Timary, P., and Mikolajczak, M. (2013). Oxytocin increases willingness to socially share one's emotions. Int. J. Psychol. 48, 676-681. doi: 10.1080/00207594.2012.677540

Lane, R. D. (2008). Neural substrates of implicit and explicit emotional processes: a unifying framework for psychosomatic medicine. Psychosom. Med. 70, 214-231. doi: 10.1097/PSY.0b013e3181647e44

Lieberman, M. D., Inagaki, T. K., Tabibnia, G., and Crockett, M. J. (2011). Subjective responses to emotional stimuli during labeling, reappraisal, and distraction. Emotion 11, 468. doi: $10.1037 / \mathrm{a} 0023503$ 
Luminet, O., Grynberg, D., Ruzette, N., and Mikolajczak, M. (2011). Personality-dependent effects of oxytocin: greater social benefits for high alexithymia scorers. Biol. Psychol. 87, 401-406. doi: 10.1016/j.biopsycho.2011.05.005

Luminet, O., Vermeulen, N., Demaret, C., Taylor, G. J., and Bagby, R. M. (2006). Alexithymia and levels of processing: evidence for an overall deficit in remembering emotion words. J. Res. Pers. 40, 713-733. doi: 10.1016/j.jrp.2005.09.001

Lumley, M. A., Neely, L. C., and Burger, A. J. (2007). The assessment of alexithymia in medical settings: implications for understanding and treating health problems. J. Pers. Assess. 89, 230-246. doi: $10.1080 / 00223890701629698$

Macdonald, K., and Feifel, D. (2013). Helping oxytocin deliver: considerations in the development of oxytocin-based therapeutics for brain disorders. Front. Neurosci. 7:35. doi: 10.3389/fnins.2013.00035

Mathews, A., and MacLeod, C. (2002). Induced processing biases have causal effects on anxiety. Cogn. Emot. 16, 331-354. doi: 10.1080/02699930143000518

Matsuzaki, M., Matsushita, H., Tomizawa, K., and Matsui, H. (2012). Oxytocin: a therapeutic target for mental disorders. J. Physiol. Sci. 62, 441-444. doi: 10.1007/s12576-012-0232-9

McCallum, M., Piper, W. E., Ogrodniczuk, J. S., and Joyce, A. S. (2003). Relationships among psychological mindedness, alexithymia and outcome in four forms of short term psychotherapy. Psychol. Psychother. 76, 133-144. doi: 10.1348/147608303765951177

Meganck, R., Vanheule, S., Inslegers, R., and Desmet, M. (2009). Alexithymia and interpersonal problems: a study of natural language use. Pers. Individ. Diff. 47, 990-995. doi: 10.1016/j.paid.2009. 08.005

Mihara, M., Miyai, I., Hattori, N., Hatakenaka, M., Yagura, H., Kawano, T., et al. (2012). Neurofeedback using real-time near-infrared spectroscopy enhances motor imagery related cortical activation. PLos ONE 7:e32234. doi: 10.1371/ journal.pone.0032234

Moriguchi, Y., Ohnishi, T., Lane, R. D., Maeda, M., Mori, T., Nemoto, K., et al. (2006). Impaired self-awareness and theory of mind: an fMRI study of mentalizing in alexithymia. Neuroimage
32, 1472-1482. doi: 10.1016/j.neuroimage.2006. 04.186

Nowakowski, M. E., McFarlane, T., and Cassin, S. (2013). Alexithymia and eating disorders: a critical review of the literature. J. Eat. Disord. 1, 21. doi: 10.1186/2050-2974-1-21

Ogrodniczuk, J. S., Piper, W. E., and Joyce, A S. (2011). Effect of alexithymia on the process and outcome of psychotherapy: a programmatic review. Psychiatry Res. 190, 43-48. doi: 10.1016/j.psychres.2010.04.026

Rota, G., Sitaram, R., Veit, R., Erb, M., Weiskopf, N., Dogil, G., et al. (2009). Self-regulation of regional cortical activity using real-time fMRI: the right inferior frontal gyrus and linguistic processing. Hum. Brain Mapp. 30, 1605-1614. doi: 10.1002/hbm.20621

Rotenberg, V. S. (1994). An integrative psychophysiological approach to brain hemisphere functions in schizophrenia. Neurosci. Biobehav. Rev. 18, 487-495. doi: 10.1016/0149-7634(94) 90003-5

Ruiz, S., Lee, S., Soekadar, S. R., Caria, A., Veit, R., Kircher, T., et al. (2013). Acquired selfcontrol of insula cortex modulates emotion recognition and brain network connectivity in schizophrenia. Hum. Brain Mapp. 34, 200-212. doi: 10.1002/hbm.21427

Salminen, J. K., Saarijärvi, S., Äärelä, E., Toikka, T., and Kauhanen, J. (1999). Prevalence of alexithymia and its association with sociodemographic variables in the general population of Finland. J. Psychosom. Res. 1, 75-82. doi: 10.1016/S00223999(98)00053-1

Sifneos, P. E. (1973). The prevalence of 'alexithymic' characteristics in psychosomatic patients. Psychother. Psychosom. 22, 255-262. doi: 10.1159/000286529

Spek, V., Nyklíèek, I., Cuijpers, P., and Pop, V. (2008). Alexithymia and cognitive behaviour therapy outcome for subthreshold depression. Acta Psychiatr. Scand. 118, 164-167. doi: 10.1111/j.1600-0447.2008.01199.x

Suslow, T., and Junghanns, K. (2002). Impairments of emotion situation priming in alexithymia. Pers. Individ. Diff. 32, 541-550. doi: 10.1016/S01918869(01)00056-3

Swart, M., Kortekaas, R., and Aleman, A. (2009). Dealing with feelings: characterization of trait alexithymia on emotion regulation strategies and cognitive-emotional processing. PLOS ONE 4:e5751. doi: 10.1371/journal.pone.0005751

Takei, Y., Suda, M., Aoyama, Y., Yamaguchi, M., Sakurai, N., Narita, K., et al. (2013). Temporal lobe and inferior frontal gyrus dysfunction in patients with schizophrenia during face-to-face conversation: a near-infrared spectroscopy study. J. Psychiatr. Res. 47, 1581-1589. doi: 10.1016/j. jpsychires.2013.07.029

Taylor, G. J., and Bagby, R. M. (2004). New trends in alexithymia research. Psychother. Psychosom. 73, 68-77. doi: 10.1159/000075537

Tolmunen, T., Lehto, S. M., Heliste, M., Kurl, S., and Kauhanen, J. (2010). Alexithymia is associated with increased cardiovascular mortality in middleaged Finnish men. Psychosom. Med. 72, 187-191. doi: 10.1097/PSY.0b013e3181c65d00

Tops, M., Koole, S. L., IJzerman, H., and BuismanPijlman, F. T. A. (2013). Why social attachment and oxytocin protect against addiction and stress: insights from the dynamics between ventral and dorsal corticostriatal systems. Pharmacol. Biochem. Behav. 4:761. doi: 10.1016/j.pbb.2013.07.015

van der Velde, J., Servaas, M. N., Goerlich, K. S., Bruggeman, R., Horton, P., Costafreda, S. G., et al. (2013). Neural correlates of alexithymia: a meta-analysis of emotion processing studies. Neurosci. Biobehav. Rev. 37, 1774-1785. doi: 10.1016/j.neubiorev.2013.07.008

Received: 21 October 2013; accepted: 29 October 2013 published online: 19 November 2013.

Citation: Samur D, Tops M, Schlinkert C, Quirin M, Cuijpers P and Koole SL (2013) Four decades of research on alexithymia: moving toward clinical applications. Front. Psychol. 4:861. doi: 10.3389/fpsyg.2013.00861 This article was submitted to Cognition, a section of the journal Frontiers in Psychology.

Copyright (c) 2013 Samur, Tops, Schlinkert, Quirin, Cuijpers and Koole. This is an open-access article distributed under the terms of the Creative Commons Attribution License (CC BY). The use, distribution or reproduction in other forums is permitted, provided the original author(s) or licensor are credited and that the original publication in this journal is cited, in accordance with accepted academic practice. No use, distribution or reproduction is permitted which does not comply with these terms. 